\title{
An Electrocatalytic System that Mimics the Catalytic Oxidation of Biogenic Mono- and Polyamines by Semicarbazide-Sensitive Amine Oxidases (SSAOs)
}

\author{
Martine Largeron $^{\mathrm{a}^{*}}$, Maurice-Bernard Fleury ${ }^{\mathrm{a}}$, and Margherita Strolin Benedetti ${ }^{\mathrm{b}}$ \\ ${ }^{a}$ UMR 8638 CNRS-Université Paris Descartes, Faculté des Sciences Pharmaceutiques et \\ Biologiques, 4 avenue de l'Observatoire, 75270 Paris Cedex 06, France \\ ${ }^{\mathrm{b}}$ UCB Pharma, 21 rue de Neuilly, 92003 Nanterre Cedex, France \\ Chemoselective oxidation of primary aliphatic biogenic mono- \\ and polyamines into imines has been successfully achieved, under \\ metal-free conditions, by using an electrocatalytic system that \\ mimics the activity of semicarbazide-sensitive amine oxidase \\ (SSAO) enzymes. Accordingly, high catalytic performance was \\ observed with unbranched primary amines such as methylamine \\ and aminoacetone, and with the primary amino groups of \\ diamines and polyamines like putrescine and spermidine, all of \\ them being reference substrates for SSAO enzymes. Furthermore, \\ contrary to flavin-adenine dinucleotide (FAD)-dependent amine \\ oxidase enzymes, no activity was found with secondary and \\ tertiary amines. Finally, when compared with the direct \\ electrochemical oxidation of primary aliphatic amines, which \\ occurs at high anodic potential $\left(\mathrm{E}_{\mathrm{an}}>+1.5 \mathrm{~V}\right.$ vs $\left.\mathrm{SCE}\right)$ and led to \\ unstable cation radicals that rapidly deprotonate and attach to the \\ electrode surface ( $\mathrm{Pt}$, carbon), 1.0 V was gained using this \\ electrocatalytic process $\left(\mathrm{E}_{\mathrm{an}}=+0.5 \mathrm{~V}\right.$ vs $\left.\mathrm{SCE}\right)$.
}

\section{Introduction}

Amine oxidases are ubiquitous enzymes which catalyze the oxidation of amines. They have been divided into two main categories depending on the cofactor involved in the catalytic process (1). First, FAD-dependent amine oxidases, which encompasse monoamine oxidases (MAO A and MAO B), and polyamine oxidases (PAOs), are characterized by the presence of flavine adenine dinucleotide (FAD) residue as the redox cofactor. Second, copper amine oxidases (CuAOs), which include in particular semicarbazide-sensitive amine oxidases (SSAOs), are enzymes possessing tightly bound $\mathrm{Cu}^{\mathrm{II}}$ and a quinone cofactor such as 2,4,5-trihydroxyphenylalanine quinone (TPQ) (Figure 1) (2).
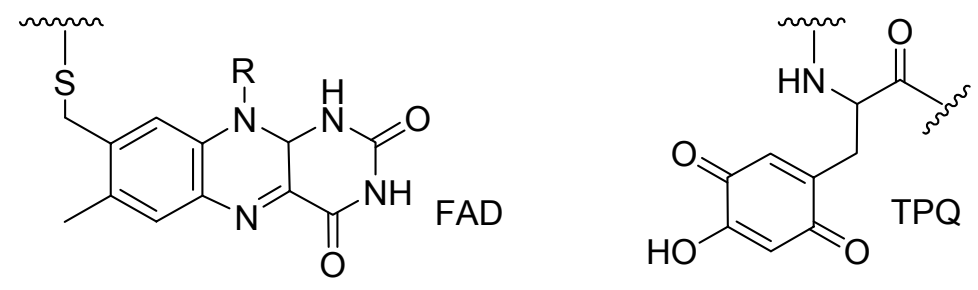

Figure 1. Chemical structure of flavin-adenine dinucleotide (FAD) and topaquinone (TPQ) redox cofactors. 
The role of SSAOs is to regulate levels of biogenic mono- and polyamines by catalyzing their oxidative deamination, because xenobiotic amines can induce toxic effects if they accumulate excessively. This is the case, for example, of putrescine and spermidine which have been recognized to be ubiquitous metabolites and physiological substrates for SSAOs (3). However, the aldehyde oxidation products are also known to produce toxic effects, so that SSAOs are implicated in a number of human pathologies $(4,5)$. As an example, aminoacetone, which is an endogenous threonine catabolite (6), affords methylglyoxal which causes proteins to aggregate and to crosslink. This type of modification is very abundant in diabetic tissues and in Alzheimer's brain.

It is well established that TPQ catalyzes the conversion of a primary amine substrate into an aldehyde through a ping-pong mechanism $(7,8)$. The reductive half reaction (ping), which involves amine oxidation into aldehyde, results in the reduction of TPQ $\left(Q_{o x}\right)$ into an aminoquinol form $\left(\mathrm{Q}_{\mathrm{red}}\right)$. The oxidative half reaction (pong) corresponds to the reduction of dioxygen to hydrogen peroxide (Scheme 1).

$$
\begin{aligned}
& \mathrm{Q}_{\mathrm{ox}}+\mathrm{R}-\mathrm{CH}_{2}-\mathrm{NH}_{3}^{+} \rightarrow \mathrm{Q}_{\text {red }}+\mathrm{R}-\mathrm{CHO} \text { (ping) } \\
& \mathrm{Q}_{\text {red }}+\mathrm{O}_{2} \rightarrow \mathrm{Q}_{\mathrm{ox}}+\mathrm{H}_{2} \mathrm{O}_{2}+\mathrm{NH}_{4}^{+} \text {(pong) }
\end{aligned}
$$

\section{Scheme 1. Ping-pong mechanism}

Although there is no question regarding the crucial role of $\mathrm{Cu}^{\mathrm{II}}$ ion cofactor in the biogenesis of TPQ, its role during the catalytic process is less well understood. However, studies have indicated that probably it stabilizes the superoxide ion intermediate formed in the course of the reduction of $\mathrm{O}_{2}$ to $\mathrm{H}_{2} \mathrm{O}_{2}(9)$.

A few years ago, we found that electrogenerated $o$-iminoquinone $\mathbf{1}_{\mathbf{0 x}}$ behaved as an effective biomimetic catalyst for the oxidation of primary aliphatic monoamines $(10,11)$. Note the analogy of the structure of TPQ (Figure 1) with that of the electrocatalyst $\mathbf{1}_{\mathbf{o x}}$ (Scheme 2). The catalytic cycle produced the reduced catalyst $\mathbf{1}_{\text {red }}$ and $N$-alkylidene alkylamine as the product of amine oxidation (Scheme 2). Interestingly, this biomimetic electrocatalytic system displayed two features that are most often associated with enzymatic systems. First, the reaction was enhanced through the participation of 1-acetyl and 2-hydroxyl substituents, as they prevented the competing formation of Michael adducts. Second, the presence of the active 2-hydroxyl group, which was engaged in an intramolecular hydrogen bond with the imine nitrogen to form a highly reactive Schiff base cyclic transition state $\mathbf{1}$ ', ox, constituted a prerequisite to the development of the catalytic process (12). Note, this process is the analog of the ping-pong mechanism previously described for the enzyme, but $\mathrm{N}$-alkylidenealkylamine was evidenced instead of aldehyde, because methanol was used as the solvent, in place of aqueous solution. Consequently, no hydrolysis into aldehyde took place.

In this paper, we report the catalytic efficiency of the electrocatalyst $\mathbf{1}_{\mathbf{o x}}$ using different biogenic mono- and polyamines which are substrates for SSAO enzymes, and we demonstrate that $\mathbf{1}_{\mathbf{o x}}$ exhibits the same substrate specificity as the SSAO enzymes, whereas markedly differing from FAD-dependent amine oxidase enzymes. 


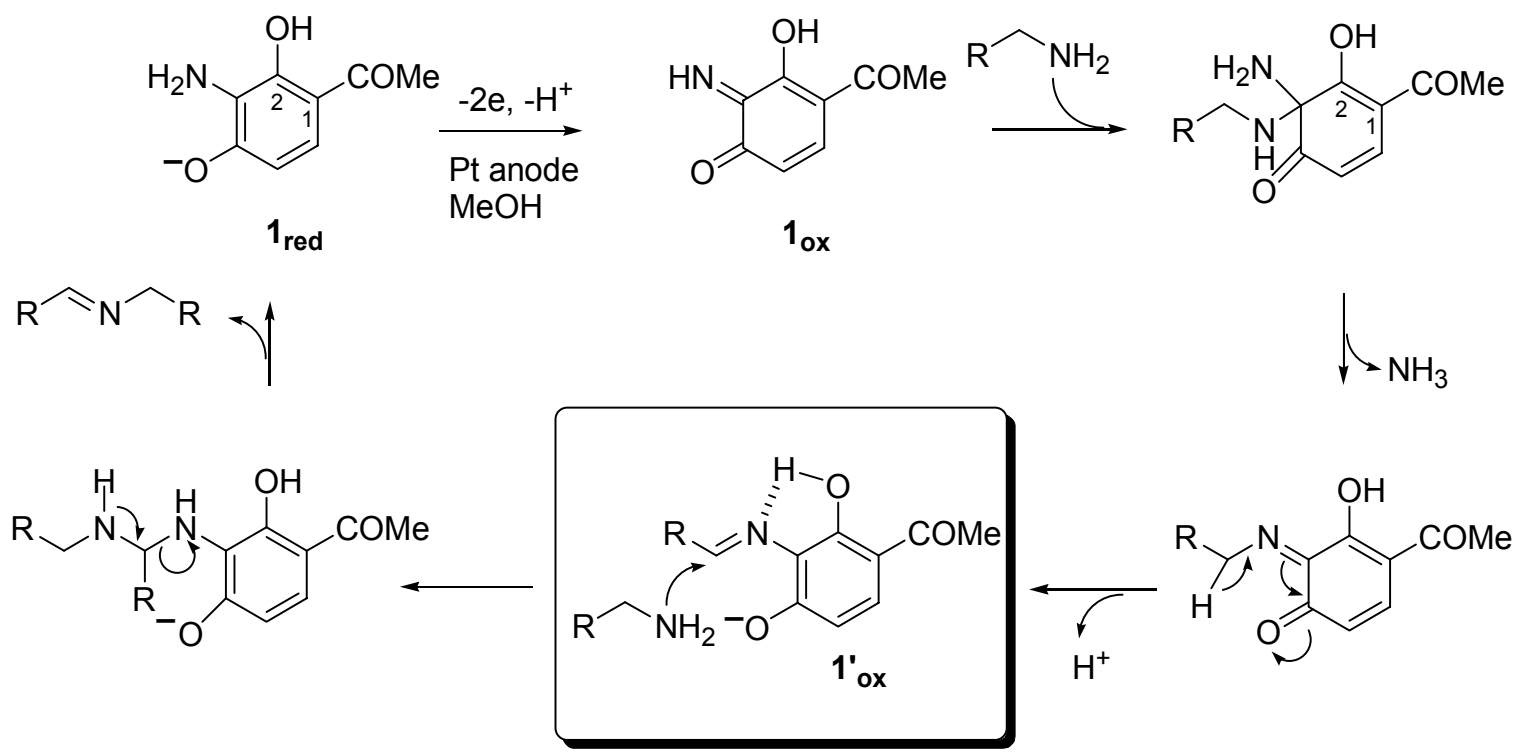

Scheme 2. $\mathbf{1}_{\mathbf{o x}}$-mediated catalytic oxidation of primary aliphatic amines into imines

\section{Experimental}

General procedure - Controlled-potential electrolysis was carried out in a cylindrical, three-electrode divided cell ( $9 \mathrm{~cm}$ diameter), using an electronic potentiostat. In the main compartment, a platinum grid $\left(60 \mathrm{~cm}^{2}\right.$ area) served as the anode (working electrode). In the specific case of putrescine and spermidine, the platinum grid was replaced by a mercury pool because polyamines spontaneously attached to the electrode surface (13). A platinum sheet was placed in the concentric cathodic compartment (counter electrode), which was separated from the main compartment with a glass frit. The reference electrode was an aqueous saturated calomel electrode (SCE), which was isolated from the bulk solution in a glass tube with a fine-porosity frit. The electrolyte solution $\left(0.1 \mathrm{~mol} . \mathrm{L}^{-1}\right.$ lithium perchlorate in methanol) was poured into the anodic and the cathodic compartments, as well as into the glass tube that contained the SCE electrode. Reduced catalyst $\mathbf{1}_{\text {red }}(0.1 \mathrm{mmol})$ and an excess of primary aliphatic amine $(5 \mathrm{mmol})$ were then added to the solution in the main compartment $(250 \mathrm{~mL})$, and the resulting solution was oxidized, under nitrogen, at room temperature, at $+500 \mathrm{mV}$ vs SCE (initial current 30-40 $\mathrm{mA})$. After exhaustive electrolysis, that is when a negligible current was recorded (0.5-1.0 mA), the solution was worked-up by the addition of 2,4-dinitrophenylhydrazine reagent $\left(2.5 \mathrm{mmol}\right.$ in $5 \mathrm{~mL}$ of pure $\mathrm{H}_{2} \mathrm{SO}_{4}, 15 \mathrm{~mL}$ of EtOH, and $5 \mathrm{~mL}$ of water) (14), the stoechiometry reflecting the fact that $5 \mathrm{mmol}$ of the primary amine gave only $2.5 \mathrm{mmol}$ of the $N$-alkylidenealkylamine (scheme 2). After $1 \mathrm{~h}$, the resulting solution was concentrated to a volume of $40 \mathrm{~mL}$. The solid obtained was collected by filtration, washed with water and dried in a vacuum desiccator. The identity and purity of 2,4dinitrophenylhydrazone (DNPH) was confirmed by TLC and ${ }^{1} \mathrm{H}$ NMR spectroscopy, after comparison with an authentic sample. 


\section{Results and Discussion}

\section{1 $\underline{\text { ox}}$-Mediated Oxidation of Monoamines}

First, we examined the catalytic efficiency of $\mathbf{1}_{\mathbf{o x}}$ toward different primary monoamines which are substrates for SSAO enzymes. Benzylamine, which is a good exogenous substrate, was chosen as the reference compound. The cyclic voltammogram of compound $\mathbf{1}_{\text {red }}(0.4 \mathrm{mM})$, in deaerated $\mathrm{MeOH}$, showed an oxidation peak at $+500 \mathrm{mV}$ vs SCE, due to a two-electron process, the sweep rate being $0.1 \mathrm{Vs}^{-1}$. The addition of benzylamine $(20 \mathrm{mM})$ had two effects: a shift of the anodic peak to $0 \mathrm{mV}$ vs SCE as a result of the ionization of the 4-hydroxyl group, and a slight increase in the anodic peak intensity, which suggested that $o$-iminoquinone $\mathbf{1}_{\mathbf{o x}}$ was protected from its succeeding polymerization reaction, because it acted as a catalyst for the oxidation of amine. Similar effects have already been observed about the catalytic activity of quinonoid species (15).

After the anodic potential was determined by cyclic voltammetry, controlled potential electrolysis was used as a preparative method for the isolation of the products resulting from the catalytic oxidation of benzylamine. When the controlled potential of the $\mathrm{Pt}$ anode was fixed at $+500 \mathrm{mV}$ vs. SCE, the anodic current remained constant for a long time, and the current efficiency obtained by the electrolysis for $7 \mathrm{~h}$ was $100 \%$, indicating that no side reaction took place under the experimental conditions used (Table 1) (12). Note that a high potential value was intentionally chosen, because of the continuous shift of the anodic peak observed in the course of the electrolysis until +500 $\mathrm{mV}$ vs. SCE, when the amine concentration was no more sufficient to ionize the 4hydroxyl group of $\mathbf{1}_{\text {red }}$. These results indicated that the $\mathbf{1}_{\text {red }} / \mathbf{1}_{\mathbf{o x}}$ system behaved as a redox mediator for the indirect electrochemical oxidation of benzylamine to the corresponding $\mathrm{N}$-benzylidenebenzylamine, according to reaction scheme 2. After exhaustive controlled potential electrolysis, $\mathrm{N}$-benzylidenebenzylamine was isolated by converting to the 2,4dinitrophenylhydrazone (DNPH), obtained upon workup of the oxidized solution with 2,4-dinitrophenylhydrazine under aqueous acidic conditions (See Experimental). Note the yield could not exceed $50 \%$, because $5 \mathrm{mmol}$ of benzylamine only gave $2.5 \mathrm{mmol}$ of $\mathrm{N}$ benzylidenebenzylamine. Furthermore, control studies confirmed that the amount of $\mathrm{N}$ benzylidenebenzylamine, produced either from simple autoxidation or from electrochemical oxidation of benzylamine in the absence of catalyst $\mathbf{1}_{\mathbf{o x}}$, was negligible. After exhaustive electrolysis, the catalyst $\mathbf{1}_{\mathbf{o x}}$ was lost irreversibly, as corroborated by the anodic current, which remained negligible upon further addition of benzylamine. Finally, the $\mathbf{1}_{\mathbf{o x}}$-mediated oxidation of benzylamine reference compound gave the corresponding $\mathrm{N}$-benzylidenebenzylamine, in quantitative yield since the current efficiency and the yield of DNPH reached 100\% and 50\%, respectively (Table 1).

Non-activated aliphatic primary monoamines also proved good substrates for the catalyst $\mathbf{1}_{\mathbf{o x}}$ (Table 1$)$. In the specific case of methylamine, the current efficiency $(50 \%)$ was roughly halved whereas no DNPH could be detected as a result of conversion of methylamine into an alkylimine which produced volatile formaldehyde on the time scale of anodic electrolysis. As a proof, when butylamine was used as the amine substrate $30 \%$ of DNPH could be isolated as roughly expected on the basis of the current efficiency (70\%). Interestingly, $o$-iminoquinone $\mathbf{1}_{\mathbf{o x}}$ was effective in oxidizing aminoacetone, that is a good endogenous substrate for SSAOs, since the current efficiency and the yield of 
DNPH reached $94 \%$ and $44 \%$, respectively. Note aminoacetone was used as its masked acetal because of the unstability of the free form. As shown in table I, the electrocatalyst $\mathbf{1}_{\mathbf{o x}}$ exhibited the same substrate specificity as the SSAO enzymes, that is poor reactivity with $\alpha$-branched primary amines and no reactivity toward secondary and tertiary (data not shown) amines.

TABLE I. $1_{\mathbf{o x}}$-mediated oxidation of SSAOs monoamine substrates ${ }^{a}$.

\begin{tabular}{|c|c|c|c|c|}
\hline \multirow[t]{2}{*}{ Monoamine Substrate } & \multirow[t]{2}{*}{ Produced Aldehyde } & \multirow{2}{*}{$\begin{array}{l}\text { Current } \\
\text { Efficiency }\end{array}$} & \multicolumn{2}{|c|}{ Yield of DNPH \% } \\
\hline & & & vs Amine & vs $1_{0 \mathrm{x}}$ \\
\hline $\mathrm{Ph} \frown \mathrm{NH}_{2}$ & $\mathrm{PhCHO}$ & 100 & 50 & 2500 \\
\hline $\mathrm{MeNH}_{2}$ & $\mathrm{HCHO}$ & 50 & $-{ }^{b}$ & $-{ }^{b}$ \\
\hline $\mathrm{NH}_{2}$ & $\mathrm{MeCH}_{2} \mathrm{CH}_{2} \mathrm{CHO}$ & 70 & 30 & 1500 \\
\hline $\begin{array}{l}\mathrm{MeO} \mathrm{NH}_{2} \\
\text { masked aminoacetone }\end{array}$ & $\begin{array}{l}\text { MeCOCHO } \\
\text { methylglyoxal }\end{array}$ & 94 & 44 & 2200 \\
\hline${ }_{\mathrm{MeO}}^{\mathrm{MeO}}$ & $\mathrm{MeCOCHO}$ & 30 & 14 & 700 \\
\hline $\mathrm{NH}^{\prime}$ & $\mathrm{CHOCHO}$ & - & 0 & 0 \\
\hline
\end{tabular}

\section{1 $\underline{\text { ox}}$-Mediated Oxidation of Polyamines}

In a second series of experiments, we investigated the catalytic efficiency of the electrocatalyst $\mathbf{1}_{\mathbf{0 x}}$ toward polyamines. Endogenous putrescine and spermidine were chosen as they are good substrates for SSAOs. Unfortunately, as previously reported (13), polyamines spontaneously attached to the platinum anode which, consequently, was replaced by a mercury pool whose potential was fixed at $0.0 \mathrm{~V}$ vs. SCE. In this case, no shift of the anodic peak was observed in the course of the electrolysis due to the presence of other amine functions, which allowed to maintain constant the basicity of the medium. Under these experimental conditions, high current efficiencies were obtained for the $\mathbf{1}_{\mathbf{o x}} \mathbf{}^{-}$ mediated oxidation of both polyamines (Table II). However, for spermidine, no DNPH could be evidenced because the catalytic process produced an alkylimine which, under aqueous acidic conditions, afforded an unstable aldehyde. The latter spontaneously decomposed into volatile acrolein (16) and putrescine which could be isolated as an insoluble ammonium sulfate.

TABLE II. 1 $_{\mathbf{0 x}}$-mediated oxidation of SSAOs polyamine substrates ${ }^{a}$.

\begin{tabular}{llll}
\hline Monoamine Substrate & Produced Aldehyde & $\begin{array}{l}\text { Current } \\
\text { Efficiency }\end{array}$ & \multicolumn{2}{c}{$\begin{array}{c}\text { Yield of DNPH \% } \\
\text { vs Amine }\end{array}$} \\
vs $\mathbf{1}_{\mathbf{o x}}$
\end{tabular}




\section{Conclusion}

Chemoselective oxidation of primary aliphatic amines to imines has been successfully achieved, under metal-free conditions, by using the electrogenerated $o$-iminoquinone mediator $\mathbf{1}_{\mathbf{o x}}$. When compared with the direct electrochemical oxidation of primary aliphatic amines, which occurs at high anodic potential $\left(\mathrm{E}_{\mathrm{an}}>+1.5 \mathrm{~V}\right.$ vs SCE) and led to unstable cation radicals that rapidly deprotonate and attach to the electrode surface $(\mathrm{Pt}$, carbon) $(17,18), 1.0 \mathrm{~V}$ was gained using this $\mathbf{1}_{\mathbf{o x}}$-mediated oxidation $\left(\mathrm{E}_{\mathrm{an}}=+0.5 \mathrm{~V}\right.$ vs $\mathrm{SCE})$.

Finally, using diverse biogenic mono- and polyamines, we have demonstrated that the electrocatalyst $\mathbf{1}_{\mathbf{0 x}}$ presents the chemoselectivity observed for the SSAO enzymes that is, high reactivity with unbranched primary amines and with the primary amino group of diamines and polyamines. Contrary to FAD-dependent amine oxidases, no activity was observed with secondary and tertiary amines (Table III).

TABLE III. Substrate specificity for amine oxidase enzymes.

\begin{tabular}{|c|c|c|c|c|c|}
\hline Substrate & $\begin{array}{l}\text { MAO A } \\
\text { FAD enzyme } \\
\end{array}$ & $\begin{array}{l}\text { MAO B } \\
\text { FAD enzyme } \\
\end{array}$ & $\begin{array}{l}\text { PAO } \\
\text { FAD enzyme }\end{array}$ & $\begin{array}{l}\text { SSAO } \\
\text { TPQ enzyme }\end{array}$ & $\mathbf{1}_{\mathrm{ox}}$ mimic \\
\hline Primary amine & $\times$ & $x$ & - & $x$ & $x$ \\
\hline Secondary amine & $x$ & $x$ & - & - & - \\
\hline Tertiary amine & $x$ & $x$ & - & - & - \\
\hline $\begin{array}{l}\text { Diamine, polyamine } \\
\text { (primary amino group) }\end{array}$ & - & - & - & $x$ & $x$ \\
\hline $\begin{array}{l}\text { Polyamine } \\
\text { (secondary amino group) }\end{array}$ & - & - & $x$ & - & - \\
\hline
\end{tabular}

$(\times)$ catalytic activity; $(-)$ no catalytic activity

A last question emerges whether SSAO inhibitors, such as semicarbazide derivatives, can also prevent the activity of the electrocatalyst $\mathbf{1}_{\mathbf{o x}}$. In the affirmative, this small molecule might provide important guidelines for designing inhibitors capable of regulating the SSAO human enzymes activities.

\section{References}

1. M. Strolin Benedetti, K.F. Tipton and R. Whomsley, Fundam. Clin. Pharmacol., 21, 467 (2007).

2. S.M. Janes, D. Mu, D. Wemmer, A.J. Smith, S. Kaur, D. Maltby, A.L. Burlingame and J. P. Klinman, Science, 248, 981(1990).

3. M. Henderson Pozzi, V. Gawandi and P.F. Fitzpatrick, Biochemistry, 48, 1508 (2009).

4. E. Agostinelli, G. Arancia, L. Dalla Vedova, F. Belli, M. Marra, M. Salvi and A. Toninello, Amino acids, 27, 347 (2004).

5. P. Dunkel, A. Gelain, D. Barlocco, N. Haider, K. Gyires, B. Sperlagh, K. Magyar, E. Maccioni, A. Fadda, P. Matyus, Curr. Med. Chem. 15, 1827 (2008). 
6. F. Dutra, F.S. Knudsen, D. Curi and E.J.H. Bechara, Chem. Res. Toxicol. 14, 1323 (2001).

7. M. Mure, S.A. Mills and J.P. Klinman, Biochemistry, 41, 9269 (2002).

8. M. Mure, Acc. Chem. Res. 37, 131 (2004).

9. C. Tang, J.P. Klinman, J. Biol. Chem., 276, 30575 (2001).

10. M. Largeron, A. Neudörffer and M.-B. Fleury, Angew. Chem. Int. Ed., 42, 1026 (2003).

11. M. Largeron, A. Neudörffer, M. Benoît and M.-B. Fleury, in Mechanistic and Synthetic Aspects of Organic and Biological Electrochemistry, D.G. Peters, J. Simonet and H. Tanaka Editors, PV 2003-12, p. 185, The Electrochemical Society Proceedings Series, Pennington, NJ (2003).

12. M. Largeron, A. Chiaroni and M.-B. Fleury, Chemistry-Eur. J., 14, 996 (2008).

13. I. Gallardo, J. Pinson and N. Vilà, J. Phys. Chem. B, 110, 19521 (2006).

14. P. Lue, W.-Q. Fan and X.-J. Zhou, Synthesis, 692 (1990).

15. K. Kano, N. Nakagawa, K. Takagi, T. Ikeda, J. Chem. Soc. Perkin Trans 2, 1111 (1997).

16. Y. Lee and L.M. Sayre, J. Biol. Chem., 273, 19490 (1998).

17. A. Adenier, M.M. Chehimi, I. Gallardo, J. Pinson, N. Vilà, Langmuir, 20, 8243 (2004).

18. J.L. Bourdelande, I. Gallardo, G. Guirado, J. Am. Chem. Soc. 129, 2817 (2007). 